\title{
PENGARUH KUALITAS PELAYANAN, PERSEPSI HARGA DAN CITRA MEREK TERHADAP KEPUASAN PELANGGAN PENGGUNA JASA TRANSPORTASI OJEK ONLINE (Studi Pada Pelanggan GrabBike Di Kota Medan).
}

\author{
Gloria J.M Sianipar \\ Fakultas Ekonomi Universitas HKBP Nommensen J1. Sutomo No.4A, 20235, Indonesia \\ email : sianipar.gloria28@gmail.com
}

\begin{abstract}
This research aims to analyze the impact of Service Quality, Price Perception and Brand Image on Customer Satisfaction of The User of Online Transportation (Case on The User of GrabBike in Medan). Data collection empasys a sample of 100 from 32 items using Likert Scale standard of measurement. In this research, free variables consist of service quality, price perception, and brand image. Bound variable is customer satisfaction. Testing includes test the validity, reliability test and assumptions classic. While the method of data analysis used multiple linear regression. The result of ttest showed that the service quality, price perception and brand image has a significant effect on customer satisfaction. The results of signification value for each variable, both variables $X$ and variable $Y$ is above the alpha value (0.05), resulting in acceptance of $H_{1}$ and Horejection. The result of $F$ test showed that the service quality, price perception and brand imageworked together to gave positive and significant contribute on customer satisfaction.In accordance with a multiple linear regression equation, $Y=2,689+0,106 X_{1}+0,133 X_{2}+0,141 X_{3}+e$. So in essence, variable $X$ has a significant effect at customer satisfaction. The result of this research were brand image has the highest significant effect to customer satisfaction.
\end{abstract}

Keywords: service quality, price perception, brand image, and customer satisfaction

\section{PENDAHULUAN}

Seiring dengan berkembangnya teknologi saat ini terdapat aplikasi yang mengenalkan layanan pemesanan ojek menggunakan teknologi dan memakai standar pelayanan. Sebelumnya ojek memakai sistem pangkalan berbasis wilayah di tikungan dan mulut-mulut gang. Saat ini sudah banyak penyedia jasa ojek online yang dikenal dengan nama Go-Jek, Blu-Jek, Taksi Roda Dua, GrabBike, Ojek Syar'i, Bang Ojek Aja. Semua memberikan pelayanan yang hampir sama mulai darimengantarkan orang dengan biaya yang berbeda-beda, namun dengan sistem pemesanan yang sama yaitu pemesanan melalui aplikasi telepon gengam maupun website.

Salah satu perusahaan jasa transportasi yang sedang berkembang di kota Medan adalah GrabBike. Grab (sebelumnya dikenal dengan GrabTaxi) merupakan salah satu platform $\mathrm{O} 2 \mathrm{O}($ Online to Offline) yang bermarkas di Singapura dan beroperasi di kawasan Asia Tenggara, menyediakan layanan kebutuhan sehari-hari bagi para pelanggan termasuk perjalanan, pesan-antar makanan, pengiriman barang dan pembayaran penggunaan dompet digital. Grab mempunyai visi guna merevolusi industri pertaksian di Asia Tenggara, sampaisampai dapat memberikan ketenteraman serta kenyamanan untuk pemakai kendaraan seantero Asia Tenggara. Hingga bulan Maret 2015,jumlah pemakai Grab menjangkau 3,8 juta pemakai. Grab terdapat untuk sistem operasi Android, iOS, dan BlackBerry.

Pengguna aplikasi Grab cukup memesan ojek melalui aplikasi mobile secara online dan nantinya akan dijemput oleh supir ojek yang merespon pengguna atau calon penumpang. Transaksi pembayaran dilakukan saat pengguna sampai ke tujuan kepada supir ojek. Tarif yang dikenakan bervariasi berdasarkan jarak yang ditempuh atau berdasarkan flat rate yang diberlakukan. Semakin banyaknya ojek online berdampak pada semakin ketatnya persaingan. Faktor yang menjadi penyebab terjadinya hal tersebut yakni 


\section{Volume 19 Nomor 2}

adanya persaingan harga dan banyaknya alternatif pilihan jasa ojek online. Hal ini menjadikan konsumen semakin selektif.

Kepuasan konsumen merupakan faktor yang sangat penting bagi keberadaan, kelangsungan, dan perkembangan perusahaan. Menurut Buttle (2007: 28) kepuasan konsumen membawa dampak yang besar bagi perusahaan, dengan mempertahankan dan memuaskan pelanggan saat ini jauh lebih mudah dibandingkan terus-menerus berupaya menarik atau memprospek pelanggan baru, biaya mempertahankan pelanggan lebih murah dibandingkan biaya mencari pelanggan baru. Salah satu faktor yang mempengaruhi kepuasan konsumen adalah kualitas pelayanan. Lupiyoadi dan Hamdani (2009: 65), juga mengemukakan bahwa kualitas pelayanan berpengaruh terhadap kepuasan pelanggan, dimana pelayanan yang baik berakibat lebih besar terhadap kepuasan pelanggan.

Faktor kedua yang mempengaruhi kepuasan konsumen adalah persepsi harga. Harga adalah jumlah uang (kemungkinan ditimbang beberapa barang) yang dibutuhkan untuk memperoleh beberapa kombinasi sebuah produk dan pelayanan yang menyertainya (Kotler dan Keller, 2007: 156). Ada kemungkinan bahwa konsumen memiliki ketidaksesuaian setelah melakukan pembelian karena mungkin harganya dianggap terlalu mahal atau karena tidak sesuai dengan keinginan dan gambaran sebelumnya (Handoko, 1987:32 dalam Kusumastuti, 2011: 2). Dengan demikian diperlukkan strategi penetapan harga yang tepat. Strategi penetapan harga sangat penting untuk menarik perhatian konsumen.

Faktor ketiga yang memengaruhi kepuasan pelanggan adalah citra merek.Citra merek adalah sebuah persepsi mengenai sebuah merek yang direfleksikan sebagai asosiasi yang ada di benak konsumen (Keller, 1993: 22). Citra yang baik akan mampu meningkatkan kesuksesan suatu perusahaan dan sebaliknya citra yang buruk akan memperpuruk kestabilan suatu perusahaan. Istijanto, (2005: 62) mengemukakan bahwa perusahaan yang memiliki citra atau reputasi yang baik akan mendorong konsumen membeli produk yang ditawarkan.

Penelitian ini menggunakan GrabBike sebagai objek penelitian. GrabBike sebagai transportasi layanan ojek berbasis aplikasimobile,namun GrabBiketidak terlepas dari berbagai permasalahan. Pemesanan berbasis online ini yang hanya terbatas bagi para pengguna smartphone android,sehingga pelanggannya hanya terbatas untuk kalangan tertentu saja. Notifikasi atau pemberitahuan tentang review yang mereka dapat dari seorang penumpang.Review yang buruk tentu bisa menyebabkan pengemudi kehilangan pekerjaan mereka sebagai seorangpengemudi GrabBike.Penulis sendiri pernah mengalami hal yang tidak nyaman ketika men-cancel orderan/pesanan karena menunggu terlalu lama. Penulis juga pernah memesan GrabBike tetapi pengemudi tidak pernah sampai ke alamat yang disepakati tetapi pengemudi melaporkan sudah selesai mengantarkan penulis (laporan fiktitf) ke alamat yang dituju.

Terkait dengan keselamatan ternyata perusahaan GrabBike tidak menyediakan jas hujan untuk para penumpang. Sementara itu, terkait dengan masalah harga ternyata tarif GrabBike Rp 1.750 per km untuk $12 \mathrm{~km}$ pertama, tarif di atas $12 \mathrm{~km}$ dikenai tambahan biaya Rp 3.000 per km dan biaya tambahan pada jam sibuk Rp 2.500.Tarif Go-Jek Rp 2.500 per km (jarak 0-12 km) dan diatas $12 \mathrm{~km}$ berubah menjadi Rp 3.000 rupiah pada jam sibuk, tarif minimum pada rush hour Rp 10.000 dan pada jam tidak sibuk Rp 6.000 (Tiffany dalam Finansialku.com 13 Oktober 2017).

Fenomena di atas relevan dengan hasil pra survei yang dilakukan peneliti di Kota Medan pada tanggal 15 - 16September 2018 terhadap 30 pelanggan ojek online GrabBike. Kota Medan dipilih sebagai objek penelitian karena persaingan GrabBike di Kota Medan semakin kompetitif dengan ojek onlinelainnya.

Adapun hasil pra survei yang menggambarkan ketidakpuasan beberapapelanggan ojek online GrabBike disajikan sebagai berikut : 

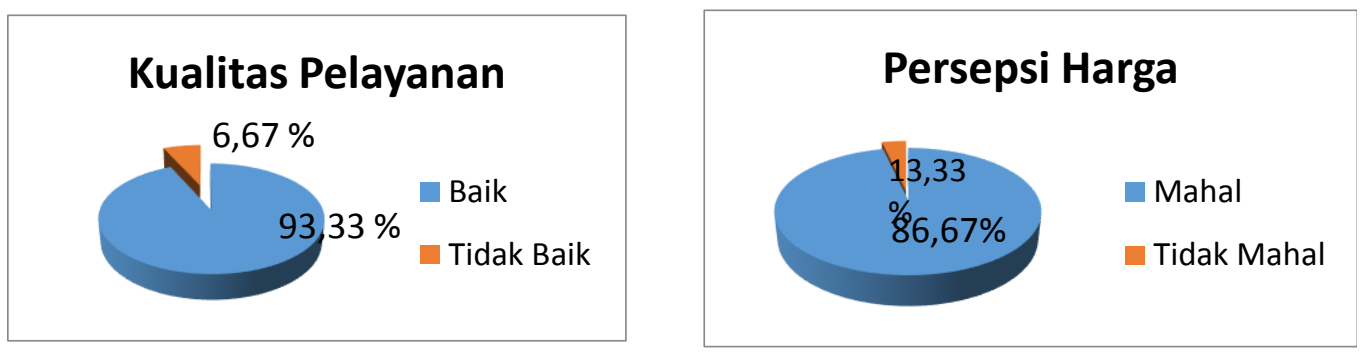

Gambar 1. Gambar 2

Hasil Pra Survei Kualitas PelayananHasil Pra Survei Persepsi Konsumenpada Ojek Online GrabBike di Kota Medan Harga Ojek Online GrabBike di Kota Medan

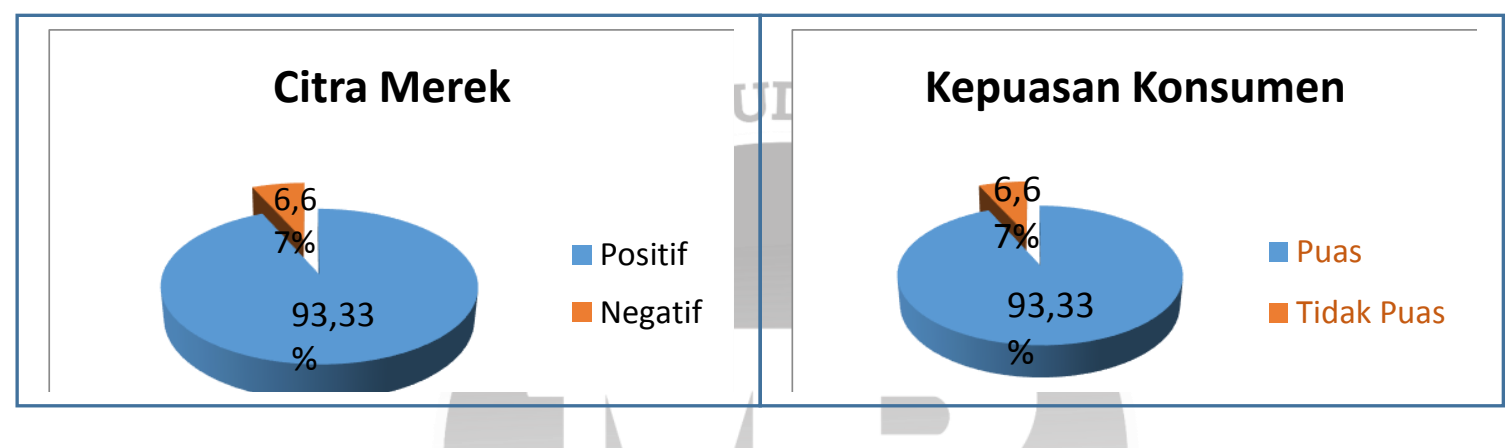

Gambar 3. Gambar 4

Hasil Pra Survei Persepsi Pelanggan pada Citra Hasil Pra Survei Kepuasan Pelanggan Merek Ojek Online GrabBike di Kota MedanPada Ojek Online GrabBike di Kota Medan

Berdasarkan latar belakang masalah yang telah diuraikan di atas, dapat dirumuskan permasalahan sebagai berikut:

1. Bagaimana pengaruh kualitas pelayanan terhadap kepuasan pelanggan pengguna jasa transportasi ojek onlineGrabBike di Kötá Medan?

2. Bagaimana pengaruh persepsi harga terhadap kepuasanpelanggan pengguna jasa transportasi ojek onlineGrabBike di Kota Medan?

3. Bagaimana pengaruh citra merek terhadap kepuasan pelanggan pengguna jasa transportasi ojek onlineGrabBike di Kota Medan?

4. Bagaimana pengaruh kualitas pelayanan, persepsi harga, dan citra merek terhadap kepuasan pelanggan pengguna jasa transportasi ojek online GrabBike di Kota Medan?

\section{TINJAUAN PUSTAKA}

\section{A. Pengertian Kepuasan Pelanggan}

"Kepuasan adalah perasaan senang atau kecewa seseorang yang timbul karena membandingkan kinerja yang dipersepsikan produk (atau hasil) terhadap ekspektasi mereka" (Kotler, 2010:138).

\section{B. Faktor-Faktor yang Memengaruhi Kepuasan Pelanggan}

Menurut Irawan (2002:40), pelanggan merasa puas jika harapannya terpenuhi. Ada lima dimensi utama kepuasan pelanggan. Dimensi pertama, adalah kualitas produk atau jasa. Dimensi kedua, adalah harga. Dimensi ketiga adalah service quality sangat tergantung pada tiga hal, yaitu sistem, teknologi dan manusia. Dimensi keempat adalah emotionalfactor. Dimensi kelima adalahkemudahan untuk mendapatkan produk atau jasa tersebut. 


\section{Pengukuran Kepuasan Pelanggan}

Kotler, et al (1996) dalam Tjiptono (2008: 34) mengidentifikasi empat metode untuk mengukur kepuasan pelanggan, yaitu sebagai berikut: (1) Sistem Keluhan dan Saran, (2) Ghost Shopping, (3) Lost Customer Analysis, (4) Survei kepuasan pelanggan. Sementara itu, kepuasaan pelanggan dalam penelitian ini diukur dengan menggunakan 3 indikator dari Consuegra (2007) yang meliputi: kesesuaian harapan, persepsi kinerja, dan penilaian pelanggan.

\section{Pengertian Kualitas Pelayanan}

Goetsch \& Davis (1994: 3)mendefinisikan kualitas pelayanan sebagai "Kualitas pelayanan merupakan suatu kondisi dinamis yang berhubungan dengan produkjasa, manusia, proses, dan lingkungan yang mampu memenuhi dan atau melebihi harapan konsumen". Kualitas pelayanan yang baik dapat menjadi keunggulan bersaing bagi perusahaan jasa seperti yang dikemukakan oleh Zeitahml, AParasuraman Berry (1996: 118) bahwa: "A second factor behind service quality's rising prominence is thatsuperior quality is proving to be winning competitive strategy. They use service to be different, they use serviceto increase productivity, they use service to earn the cutomer's loyalty, they use service to fan positive word- ofmouth advertising, they use service to seek same shelter from price competititon (Valerie A.Zeitahml, A. Parasuraman dan Leonard L.Berry, 1996)".

\section{E. Dimensi Kualitas Pelayanan}

Zeithaml (1996: 38), mengemukakan lima dimensi dalam menentukan kualitas jasa, yaitu sebagai berikut: (a) Reliability, (b) Responsiveness, (c) Assurance, (d) Emphaty, dan (e)Tangibles,

\section{F. Pengertian Persepsi}

Menurut Sarwono dan Meinarno (2009: 24), persepsi merupakan proses perolehan, penafsiran, pemilihan, dan pengaturan informasi indrawi. Informasi indrawi meliputi apa yang kita lihat, kita dengar dan yang kita rasakan.

\section{G. Harga}

\section{KATOLIK}

Kotler dan Amstrong (2001:73) mengatakan bahwa harga (price) adalah sejumlah uang yang harus dibayar oleh pelanggan untuk memperoleh produk. Variabel ini merupakan hal yang dapat dikendalikan dan menentukan diterima atau tidaknya suatu produk oleh konsumen. Harga semata-mata tergantung pada kebijakan perusahaan tetapi tentu saja dengan mempertimbangkan berbagai hal.

Peter dan Olson (2000:228) menyatakan: persepsi harga berkaitan dengan bagaimana informasi harga dipahami seluruhnya oleh konsumen dan memberikan makna yang dalam bagi mereka. Pada saat konsumen melakukan evaluasi dan penelitian terhadap harga dari suatu produk sangat dipengaruhi oleh perilaku dari konsumen itu sendiri.

Stanton menyatakan (1998: 308) ada empat indikator yang mencirikan harga adalah: (1) Keterjangkauan harga, (2) Daya saing harga, (3) Kesesuaian harga dengan kualitas produk, dan (4) Kesesuaian harga dengan manfaat produk.

\section{H. Pengertian Citra}

Pengertian citra menurut Peter dan Olson (2000:248-249) citra adalah apa yang dipikirkan konsumen tentang suatu produk. Termasukdidalamnya adalah persepsi dan sikap yang didasarkan pada reaksi dan rangsangan yang berkaitan dengan perusahaan yang diterima melalui kelima indera. Citra yang baik berarti masyarakat (khususnya konsumen) mempunyai kesan positif terhadap suatu organisasi, sehingga citra yang kurang baik berarti 


\section{Volume 19 Nomor 2}

masyarakat mempunyai kesan yang negatif (Sutisna, 2001:331). Brand image atau brand description yakni deskripsi tentang asosiasi dan keyakinan konsumen terhadap merek

tertentu (Tjiptono, 2005). Kotler (2000) dalam Irawati dan Primadha (2008) menyatakan bahwa brand image adalah sejumlah keyakinan tentang merek.

\section{Atribut Citra}

Menurut Engel, dkk (1995:249) atribut yang dominan dari citra merek tersebut, meliputi: (1) Lokasi, (2) Sifat dan kualitas keragaman produk, (3) Harga, (4) Iklan dan promosi, (5) Personal penjualan, (6) Atribut fisik produk, (7) Pelayanan dan kepuasan pasca pembelian.Menurut Davidson (1998) ada empat indikator citra merek yaitu : (1) Reputation (nama baik), tingkat atau status yang cukup tinggi dari sebuah merek produk tertentu, (2) Recognition (pengenalan), yaitu tingkat dikenalnya sebuah merek oleh konsumen, (3) Affinity (hubungan emosional), hubungan emosional yang terjadi antar brand dengan pelanggan, dan (4) Brand Loyality (loyalitas merek), seberapa jauh kesetiaan konsumen menggunakan produk dengan brand tertentu.

\section{J. Kerangka Berpikir}

1. Pengaruh Kualitas Pelayanan terhadap Kepuasan Konsumen. Kualitas pelayanan merupakan kunci untuk mencapai kesuksesan. Baik tidaknya kualitas pelayanan barang atau jasa tergantung pada kemampuan produsen dalam memenuhi harapan konsumen secara konsisten. Kualitas pelayanan dikatakan memuaskan jika layanan yang dirasakan sama atau melebihi kualitas layanan yang diharapkan. Pelayanan yang seperti inilah yang dipersepsikan sebagai pelayanan berkualitas dan ideal. Harapan konsumen tersebut tercermin pada dimensi kualitas pelayanan seperti tangibles (bukti fisik), reliability (keandalan), responsiveness (daya tanggap), assurance (jaminan), dan empathy (empati).

2. Pengaruh Persepsi Harga terhadap Kepuasan Konsumen. Apabila nilai yang dirasakan pelanggan semakin tinggi, maka akan menciptakan kepuasan konsumen yang maksimal (Tjiptono, 1999). Kertajaya (2002) mengungkapkan bahwa indikator penilaian harga dapat dilihat dari kesesuaian antara suatu pengorbanan dari konsumen terhadap nilai yang diterimanya setelah melakukan pembelian, dan dari situlah konsumen akan mempersepsi dari produk atau jasa tersebut. Persepsi yang pösitif merupakan hasil dari rasa puas akan suatu pembelian yang dilakukannya, sedangkan persepsi yang negatif merupakan suatu bentuk dari ketidakpuasan konsumen atas produk atau jasa yang dibelinya.

3. Pengaruh Citra Merek terhadap Kepuasan Konsumen. Citra merek adalah sebuah persepsi mengenai sebuah merek yang direfleksikan sebagai asosiasi yang ada di benak konsumen (Keller, 1993: 22). Asosiasi ini dapat tercipta karena pengalaman langsung dari konsumen atas barang dan jasa atau informasi yang telah dikomunikasikan oleh perusahaan itu sendiri. Citra yang baik akan mampu meningkatkan kesuksesan suatu perusahaan dan sebaliknya citra yang buruk akan memperpuruk kestabilan suatu perusahaan. Perusahaan yang memiliki citra atau reputasi yang baik akan mendorong konsumen membeli produk yang ditawarkan dan dapat menciptakan kepuasan konsumen.

4. Pengaruh Kualitas Pelayanan, Persepsi Harga, dan Citra Merek terhadap Kepuasan Konsumen. Kualitas pelayanan, harga, dan citra merek merupakan hal penting yang dapat mempengaruhi kepuasan konsumen. Parasuraman, et al. (1988:118)menyatakan bahwa kualitas pelayanan yang tinggi menghasilkan kepuasan pelanggan yang tinggi pula. Apabila pelayanan yang diterima atau dirasakan pelanggan sesuai atau bahkan melebihi harapan pelanggan, maka pelayanan tersebut dianggap berkualitas dan memuaskan. Faktor kedua yang mempengaruhi kepuasan konsumen adalah harga. Jika harga yang ditetapkan oleh sebuah perusahaan tidak sesuai dengan manfaat produk maka hal itu dapat menurunkan tingkat kepuasan pelanggan, dan sebaliknya jika harga yang 


\section{Volume 19 Nomor 2}

ditetapkan oleh sebuah perusahaan sesuai dengan manfaat yang diterima maka akan meningkatkan kepuasan pelanggan. Citra merek juga dapat mempengaruhi kepuasan pelanggan karena citra yang baik dari suatu organisasi akan mempunyai dampak yang menguntungkan, sedangkan citra yang jelek akan merugikan organisasi. Citra yang baik memberi kesan positif terhadap suatu organisasi, sehingga dapat menciptakan kepuasan.

\section{K. Paradigma Penelitian}

\section{Hipotesis Penelitian}

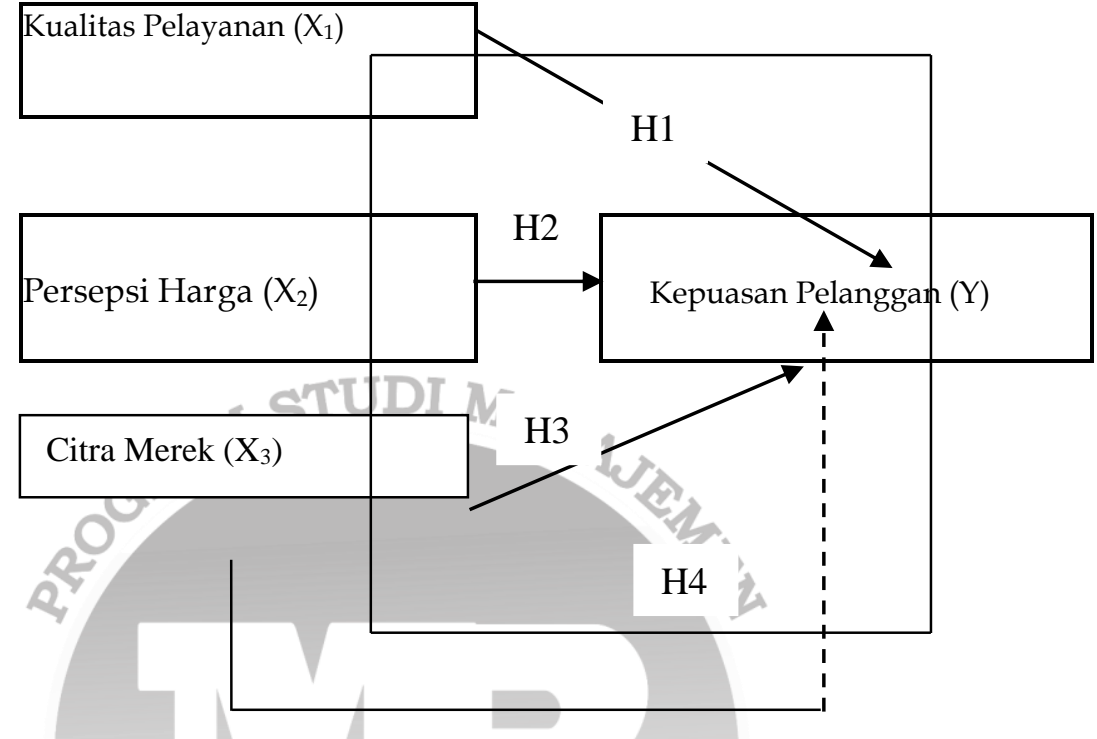

Gambar 5. Kerangka Berpikir

1. Kualitas pelayanan berpengaruh signifikan terhadap kepuasan pelanggan pengguna jasa transportasi ojek online GrabBike di Kota Medan.

2. Persepsi harga berpengaruh signifikan terhadap kepuasan pelanggan pengguna jasa transportasi ojek online GrabBike di Kota Medan.

3. Citra merek berpengaruh signifikan terhadap kepuasan pelanggan pengguna jasa transportasi ojek online GrabBike di Kota Medan.

4. Kualitas pelayanan, persepsi harga, dan citra merek secara bersama-sama berpengaruh signifikan terhadap kepuasan pelanggan pengguna jasa transportasi ojek online GrabBike di Kota Medan.

\section{METODE PENELITIAN}

Jenis penelitian yang digunakan dalam penelitian ini adalah survei. Pada penelitian survei, informasi yang dikumpulkan dari responden dengan menggunakan kuesioner. Penelitian ini berdasarkan tingkat eksplanasinya digolongkan dalam penelitian asosiatif. Penelitian ini dilaksanakan di Kota Medan. Waktu penelitian dilaksanakan mulai bulan September 2018 - Maret 2019.

\section{A. Populasi dan Sampel}

Populasi dalam penelitian ini adalah seluruh pelanggan pengguna transportasi ojek online GrabBike di Kota Medan pada bulan September 2018 hingga Januari 2019.Teknik yang digunakan dalam penelitian ini adalah purposive sampling. Sampel dalam penelitian ini adalah sebagian pelanggan GrabBike di Kota Medan. Kriteria responden yang diambil sebagaisampel adalah pelanggan yang pernah menggunakan jasa transportasi ojek online GrabBike di Kota Medan minimal dua kali selama tiga bulan terakhir.Jumlah sampel dalam 


\section{Volume 19 Nomor 2}

penelitian ini ditentukan berdasarkan pendapat dari Hair (1995) yang menemukan bahwa ukuran sampel yang sesuai adalah antara 100 sampai 200.

\section{B. Teknik Pengumpulan Data}

Penelitian ini menggunakan metode teknik pengumpulan data kuesioner (angket). Mekanisme pengumpulan data dalam penelitian inidilakukan dengan membagikan kuisioner secara manual kepada para respondendenganskalapengukuranyakniskalalikert.

Tabel 1. Operasionalisasi Variabel Penelitian : Variabel, Definisidan Indikator

\begin{tabular}{|c|c|c|}
\hline $\begin{array}{l}\text { Sub } \\
\text { Variabel }\end{array}$ & DefinisiVariabel & Indikator \\
\hline $\begin{array}{l}\text { Kualitas } \\
\text { Pelayan } \\
\text { an }\left(X_{1}\right)\end{array}$ & $\begin{array}{l}\text { Kualitas layanan merupakan } \\
\text { keseluruhan berbagai ciri dan } \\
\text { karakteristik dari suatu produk } \\
\text { atau jasa dalam hal kemampuan } \\
\text { untuk memenuhi berbagai } \\
\text { kebutuhan yang telah ditentukan } \\
\text { atau yang bersifat laten } \\
\text { (Zeitahml, Parasuraman, 1996). }\end{array}$ & $\begin{array}{l}\text { 1. Tangibles/Bukti-bukti fisik yaitu penampilan fasilitas fisik } \\
\text { seperti gedung danruangan, tersedianya tempat parkir, } \\
\text { kebersihan, kerapihan dan kenyamanan ruangan, } \\
\text { kelengkapan peralatan komunikasi, dan penampilan } \\
\text { karyawan. } \\
\text { 2. Reliability yaitu kemampuan untuk memberikan } \\
\text { pelayanan yangsesuai dengan janji yang ditawarkan. } \\
\text { 3. Responsiveness yaitu respon atau kesigapan karyawan } \\
\text { dalammembantu pelanggan dan memberikan pelayanan } \\
\text { yang cepat dan tanggap. } \\
\text { 4. Assurance yaitu kemampuan karyawan atas } \\
\text { pengetahuanterhadap produk secara tepat. } \\
\text { 5. Empathy yaitu perhatian secara individual yang diberikan } \\
\text { perusahaan kepada pelanggan. }\end{array}$ \\
\hline $\begin{array}{l}\text { Persepsi } \\
\text { Harga } \\
\left(\mathrm{X}_{2}\right)\end{array}$ & $\begin{array}{l}\text { Paul Peter dan Jerry Olson (2000:228) } \\
\text { menyatakan: persepsi harga berkaitan } \\
\text { dengan bagaimana informasi harga } \\
\text { dipahami seluruhnya oleh konsumen } \\
\text { dan memberikan makna yang dalam } \\
\text { bagi mereka. }\end{array}$ & $\begin{array}{l}\text { Stanton (1998) yang meliputi: (1) keterjangkauan } \\
\text { harga, (2) kesesuaian harga dengan kualitas } \\
\text { produk, (3) daya saing harga, dan (4) kesesuaian } \\
\text { harga dengan manfaat. }\end{array}$ \\
\hline $\begin{array}{l}\text { Citra } \\
\text { Merek } \\
\left(X_{3}\right)\end{array}$ & $\begin{array}{l}\text { Brand image atau brand description } \\
\text { yakni deskripsi tentang asosiasi } \\
\text { dan keyakinan konsumen } \\
\text { terhadap merek tertentu } \\
\text { (Tjiptono, 2005). }\end{array}$ & $\begin{array}{l}\text { (1) Reputation (nama baik), tingkat atau status yang cukup } \\
\text { tinggi dari sebuah merek produk tertentu. } \\
\text { (2) Recognition (pengenalan), yaitu tingkat dikenalnya } \\
\text { sebuah merek oleh konsumen. } \\
\text { (3) Affinity (hubungan emosional), hubungan emosional } \\
\text { (4) Brand Loyality (loyalitas merek), seberapa jauh kesetiaan } \\
\text { konsumen menggunakan produk dengan brand tertentu. } \\
\text { (Davidson (1998) }\end{array}$ \\
\hline $\begin{array}{l}\text { Kepuasa } \\
\mathrm{n} \\
\text { Pelangg } \\
\text { an } \\
(\mathrm{Y})\end{array}$ & $\begin{array}{l}\text { Kepuasan pelanggan menurut Engel } \\
\text { dkk (1990:45) adalah "evaluasi purna } \\
\text { beli dimana sekurang-kurangnya } \\
\text { memberikan hasil (outcome) sama } \\
\text { atau melampaui harapan pelanggan. }\end{array}$ & $\begin{array}{l}\text { Consuegra (2007) menyatakan bahwa kepuasan } \\
\text { pelanggan memiliki } 3 \text { indikator yaitu : (1) } \\
\text { kesesuaian harapan, (2) persepsi kinerja, dan (3) } \\
\text { penilaian pelanggan. }\end{array}$ \\
\hline
\end{tabular}

Sumber : Data diolah penulis, 2018

\section{Uji Coba Instrumen}

\section{Uji Validitas dengan Pearson Correlation}

Tabel 2 : Hasil Uji Validitas

\begin{tabular}{|l|l|l|l|l|}
\hline Variabel & Pertanyaan & Pearson Correlation & $\mathrm{r}_{\text {tabel }}$ & Keterangan \\
\hline \multirow{5}{*}{ KualitasPelayanan $\left(\mathrm{X}_{1}\right)$} & P1 & 0.348 & 0.361 & TidakValid \\
\cline { 2 - 5 } & P2 & 0.618 & 0.361 & Valid \\
\cline { 2 - 5 } & P3 & 0.396 & 0.361 & Valid \\
& P4 & 0.327 & 0.361 & TidakValid \\
& P5 & 0.548 & 0.361 & Valid \\
& P6 & 0.561 & 0.361 & Valid \\
& P7 & 0.659 & 0.361 & Valid \\
\hline
\end{tabular}


Volume 19 Nomor 2

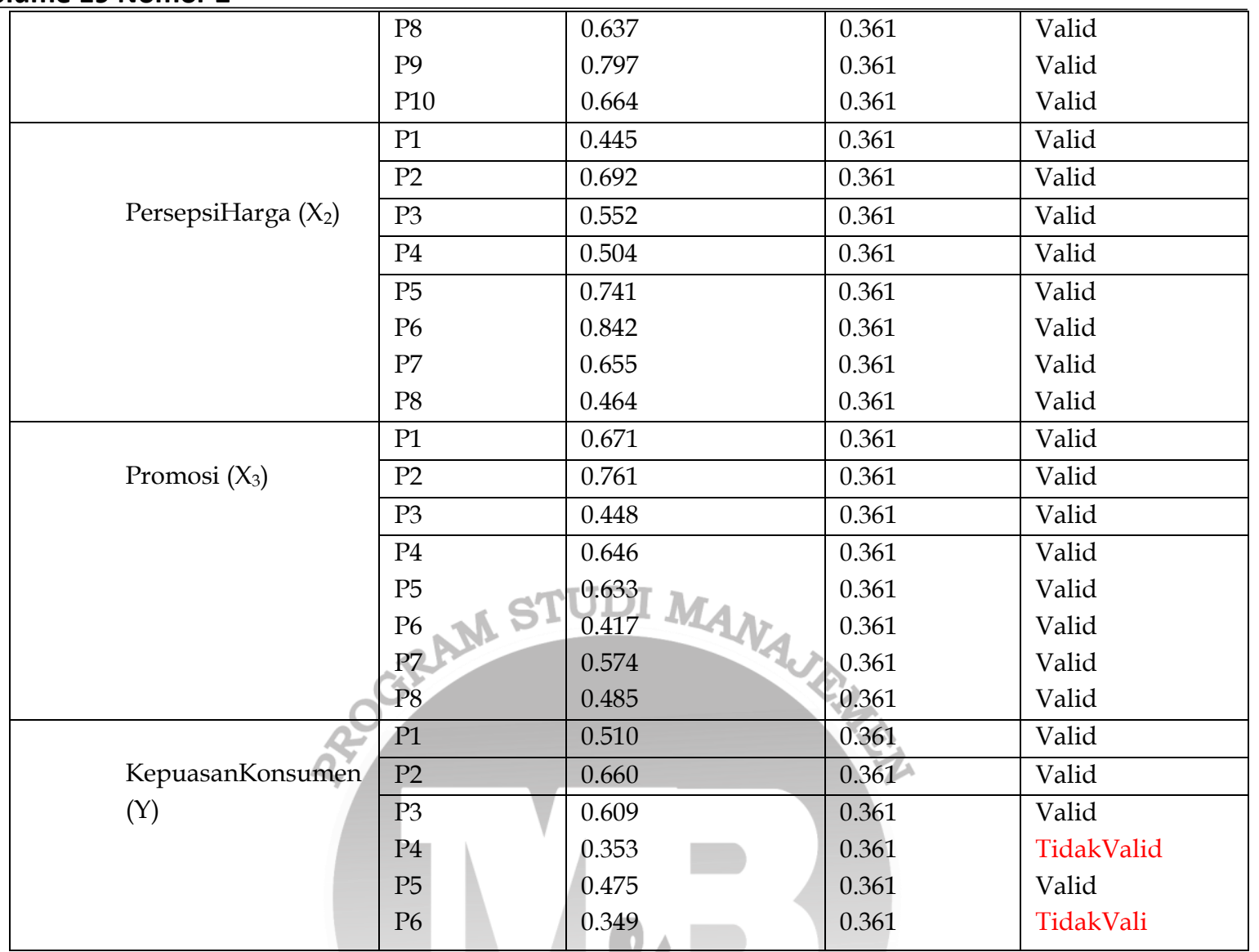

Sumber : Hasil Penelitian 2018, (data diolah)

\section{Uji Reliabilitas}

Tabel 3: Uji Reliabilitas

\begin{tabular}{|l|l|l|l|}
\hline No & Variabel & Cronbach's Alpha & Keterangan \\
\hline 1 & KualitasPelayanan $\left(\mathrm{X}_{1}\right)$ & 0.756 & Reliabilitas baik \\
\hline 2 & PersepsiHarga $\left(\mathrm{X}_{2}\right)$ & 0.748 & Reliabilitas baik \\
\hline 3 & Promosi $\left(\mathrm{X}_{3}\right)$ & 0.737 & Reliabilitas baik \\
\hline 4 & KepuasanKonsumen $(\mathrm{Y})$ & 0.679 & Reliabilitas baik \\
\hline
\end{tabular}

Sumber : Hasil penelitian 2018, (data diolah)

\section{HASIL PENELITIAN DAN PEMBAHASAN}

\section{A. Hasil Penelitian}


Tabel 4. Uji Kolmogrov-Smirnov One-Sample Kolmogorov-Smirnov Test

\begin{tabular}{|c|c|c|c|}
\hline & & & Kepuasan \\
\hline N & & & 100 \\
\hline \multirow[t]{2}{*}{ Normal Parameters ${ }^{a}$} & Mean & & 29.54 \\
\hline & Std. Deviation & & 3.963 \\
\hline \multirow[t]{3}{*}{ Most Extreme Differences } & Absolute & & .076 \\
\hline & Positive & & .076 \\
\hline & Negative & & -.076 \\
\hline Kolmogorov-Smirnov Z & & & .763 \\
\hline Asymp. Sig. (2-tailed) & & & .606 \\
\hline \multirow[t]{3}{*}{ Monte Carlo Sig. (2-tailed) } & Sig. & & $.550^{c}$ \\
\hline & 95\% Confidence Interval & Lower Bound & .452 \\
\hline & & Upper Bound & .648 \\
\hline
\end{tabular}

a. Test distribution is Normal.

c. Based on 100 sampled tables with starting seed 1502173562.

Sumber : Data Primer (2019)

Karena nilai signifikansi Monte Carlo sebesar 55\% lebih besar dari nilai alpha 5\% , maka data sudah memenuhi asumsi normalitas.

\section{Uji Multikolinieritas}

Tabel 5. Hasil Uji Multikolinieritas

\begin{tabular}{|l|c|c|l|}
\hline \multicolumn{1}{|c|}{ Variabel } & Tolerance & VIF & \multicolumn{1}{|c|}{ Kesimpulan } \\
\hline Kualitas Pelayanan & 0,824 & 1,213 & Non Multikolinieritas \\
\hline Persepsi Harga & 0,707 & 1,414 & Non Multikolinieritas \\
\hline Citra Merek & 0,843 & 1,186 & Non Multikolinieritas \\
\hline
\end{tabular}

Sumber : Data Primer (2019)

Dari tabel di atas terlihat bahwa semua variabel mempunyai nilai toleransi di atas 0,1 atau di bawah 1 dan nilai VIF di bawah 10, sehingga dapat disimpulkan bahwa model regresi pada penelitian ini tidak terjadi multikolinieritas.

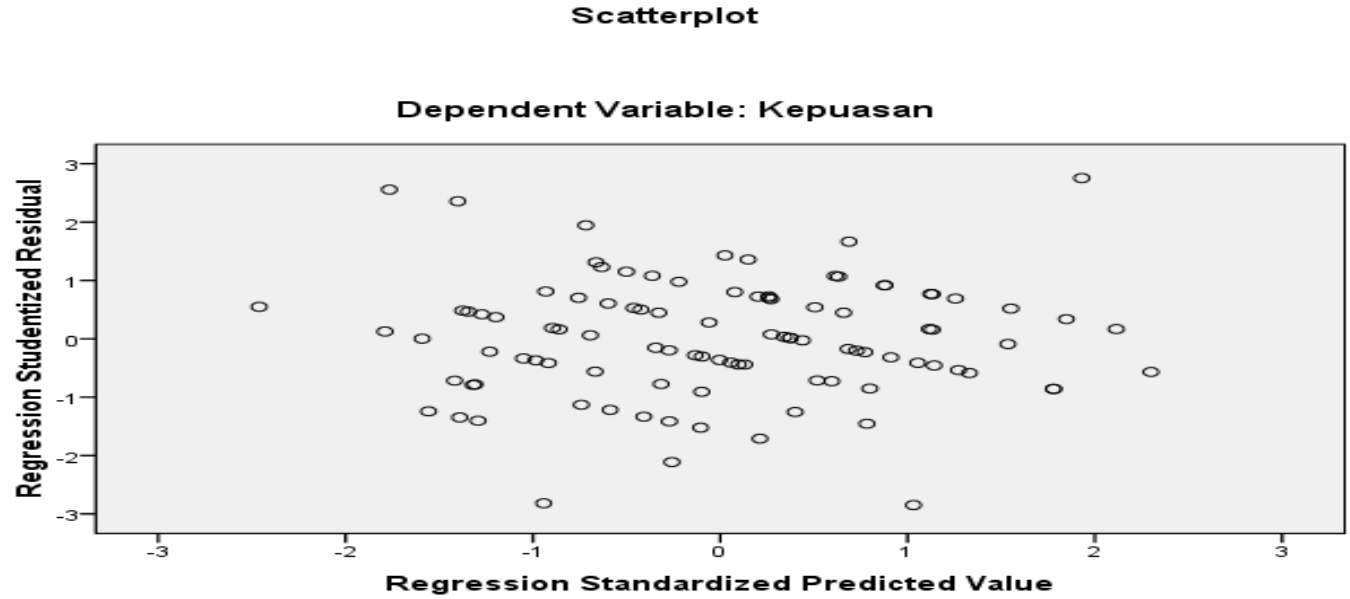

Gambar 6. Uji Heteroskedastisitas

Maka dapat disimpulkan bahwa model ini bebas dari asumsi klasik heteroskedasisitas dan lanyak digunakan dalam penelitian. 
Volume 19 Nomor 2

\section{B. Pengujian Hipotesis}

Tabel 6. Rangkuman Hasil Analisis Regresi Berganda

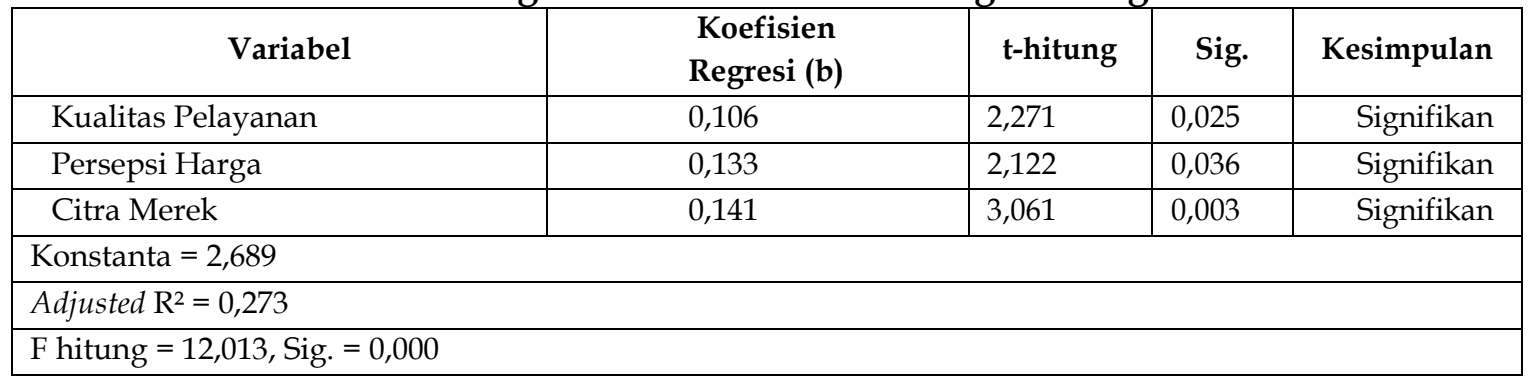

Sumber: Data Primer (2019)

Dari hasil analisis regresi dapat diketahui persamaan regresi berganda sebagai berikut:

$$
\mathrm{Y}=2,689+0,106 \mathrm{X}_{1}+0,133 \mathrm{X}_{2}+0,141 \mathrm{X}_{3}+\mathrm{e}
$$

a. Uji $\mathrm{t}$ (secara parsial).

Pengaruh kualitas pelayanan terhadap kepuasan pelanggan

Ho ditolak dan H1 diterima, atinya, ada pengaruh kualitas pelayanan terhadap kepuasan pelanggan sehingga hipotesis yang menyatakan "Kualitas pelayanan berpengaruh signifikan terhadap kepuasan pelanggan pengguna jasa transportasi ojek online GrabBike di Kota Medan" diterima.

Pengaruh persepsi harga terhadap dengan kepuasan pelanggan Ho ditolak dan H1 diterima, artinya ada pengaruh persepsi harga terhadap kepuasan pelanggan sehingga hipotesis yang menyatakan "Persepsi harga berpengaruh signifikan terhadap kepuasan pelanggan pengguna jasa transportasi ojek online GrabBike di Kota Medan" diterima.

Pengaruh citra merek terhadap kepuasan pelanggan. Ho ditolak dan H1 diterima, artinya ada pengaruh citra merek terhadap kepuasan pelanggan sehingga hipotesis yang menyatakan "Citra merek berpengaruh signifikan terhadap kepuasan pelanggan pengguna jasa transportasi ojek online GrabBike di Kota Medan" diterima.

b. Uji F (Fisher)

Ho ditolak dan H1 diterima, artinya secara serempak ada pengaruh antara kualitas pelayanan, persepsi harga dan citra merek terhadap kepuasan pelanggan sehingga hipotesis yang menyatakan "Kualitas pelayanan, persepsi harga, dan citra merek secara bersama-sama berpengaruh signifikan terhadap kepuasan pelanggan pengguna jasa transportasi ojek online GrabBike di Kota Medan" diterima.

c. Koefisien Determinasi (Adjusted $\mathrm{R}^{2}$ )

Besarnya koefisien determinasi (Adjusted $\mathrm{R}^{2}$ ) adalah 0,273. Angka tersebut mempunyai maksud bahwa pengaruh kualitas pelayanan, persepsi harga dan citra merek terhadap kualitas pelayanan secara gabungan adalah 27,3 \%, sedangkan sisanya $72,7 \%$ dipengaruhi oleh faktor lain.

\section{PEMBAHASAN}

\section{A. Pengaruh Kualitas Pelayanan terhadap Kepuasan Pelanggan}

Penelitian ini berhasil membuktikan hipotesis pertama yang menyatakan bahwa "Kualitas pelayanan berpengaruh signifikan terhadap kepuasan pelanggan pengguna jasa transportasi ojek online GrabBike di Kota Medan".Faktor pertama yang mempengaruhi kepuasan pelanggan adalah kualitas pelayanan. Lupiyoadi dan Hamdani (2009: 65) mengemukakan bahwa kualitas pelayanan berpengaruh terhadap kepuasan pelanggan, dimana pelayanan yang baik berakibat lebih besar terhadap kepuasan pelanggan.Hasil penelitian ini mendukung penelitian sebelumnya yang dilakukan oleh Mar'ati (2016) tentang 


\section{Volume 19 Nomor 2}

"Pengaruh Kualitas Layanan dan Harga terhadap Kepuasan Pelanggan Jasa Transportasi Ojek Online (Studi pada Konsumen Gojek di Surabaya)". Hasil penelitian menunjukkan bahwa kualitas layanan berpengaruh secara positif dan signifikan terhadap kepuasan pelanggan.

\section{B. Pengaruh Persepsi Harga terhadap Kepuasan Pelanggan}

Penelitian ini dapat membuktikan hipotesis kedua yang menyatakan bahwa "Persepsi harga berpengaruh signifikan terhadap kepuasan pelanggan pengguna jasa transportasi ojek online GrabBike di Kota Medan".Apabila nilai yang dirasakan pelanggan semakin tinggi, maka akan menciptakan kepuasan konsumen yang maksimal (Tjiptono, 1999). Kertajaya (2002) mengungkapkan bahwa indikator penilaian harga dapat dilihat dari kesesuaian antara suatu pengorbanan dari konsumen terhadap nilai yang diterimanya setelah melakukan pembelian, dan dari situlah konsumen akan mempersepsi dari produk atau jasa tersebut. Hasil penelitian ini mendukung penelitian sebelumnya yang dilakukan oleh Wahyuno (2013) melakukan penelitian tentang "Pengaruh kualitas pelayanan dan harga terhadap kepuasan konsumen pengguna jasa Hotel Anugerah Glagah Indah Temon Kulon Progo Yogyakarta". Hasil penelitian menunjukkan bahwa harga berpengaruh positif dan signifikan terhadap kepuasan konsumen di Hotel Anugerah Glagah Indah.

\section{Pengaruh Citra Merek terhadap Kepuasan Pelanggan}

Penelitian ini berhasil membuktikan hipotesis ketiga yang menyatakan bahwa "Citra merek berpengaruh signifikan terhadap kepuasan pelanggan pengguna jasa transportasi ojek online GrabBike di Kota Medan". Citra menurut Peter dan Olson (2000:248-249) citra adalah apa yang dipikirkan konsumen tentang suatu produk. Istijanto, (2005: 62) mengemukakan bahwa perusahaan yang memiliki citra atau reputasi yang baik akan mendorong konsumen membeli produk yang ditawarkan.Hasil penelitian ini relevan dengan penelitian dari Herliza dan Saputri (2016) tentang "Pengaruh Brand Image terhadap Kepuasan Pelanggan Studi pada Zara di Mall PVJ Bandung". Hasil penelitian menunjukkan bahwa terdapat pengaruh positif dan signifikan antara citra merek terhadap kepuasan pelanggan, artinya semakin tinggi citra merek maka kepuasan pelanggan akan meningkat.

\section{Pengaruh Kualitas Pelayanan, Persepsi Harga, dan Citra Merek terhadap Kepuasan Pelanggan}

Penelitian ini berhasil membuktikan hipotesis keempat yang menyatakan "Kualitas pelayanan, persepsi harga dan citra merek berpengaruh signifikan terhadap kepuasan pelanggan pengguna jasa transportasi ojek online GrabBike di Kota Medan".Kepuasan konsumen merupakan faktor yang sangat penting bagi keberadaan, kelangsungan, dan perkembangan perusahaan. Saat ini banyak perusahaan yang semakin memahami arti penting dari kepuasan konsumen dan menjalankan strategi guna memberikan kepuasan bagi konsumennya. Menurut Buttle (2007: 28) kepuasan konsumen membawa dampak yang besar bagi perusahaan. Dengan memertahankan dan memuaskan pelanggan saat ini jauh lebih mudah dibandingkan terus-menerus berupaya menarik atau memprospek pelanggan baru, biaya memertahankan pelanggan lebih murah dibandingkan biaya mencari pelanggan baru. Kualitas pelayanan, persepsi harga, dan citra merek merupakan hal penting yang dapat mempengaruhi kepuasan konsumen. Parasuraman, etal. (1988: 118) menyatakan bahwa kualitas pelayanan yang tinggimenghasilkan kepuasan pelanggan yang tinggi pula. Faktor kedua yang mempengaruhi kepuasan konsumen adalah persepsi harga. Jika harga yang ditetapkan oleh sebuah perusahaan tidak sesuai dengan manfaat produk maka hal itu dapat menurunkan tingkat kepuasan pelanggan, dan sebaliknya jika harga yang ditetapkan oleh sebuah perusahaan sesuai dengan manfaat yang diterima maka akan meningkatkan 


\section{Volume 19 Nomor 2}

kepuasan pelanggan. Citra merek juga dapat mempengaruhi kepuasan pelanggan. karena citra yang baik dari suatu organisasi akan mempunyai dampak yang menguntungkan, sedangkan citra yang jelek akan merugikan organisasi. Citra yang baik memberi kesan positif terhadap suatu organisasi, sehingga dapat menciptakan kepuasan.Hasil penelitian ini relevan dengan penelitian dari Mar'ati (2016) tentang "Pengaruh Kualitas Layanan dan Harga terhadap Kepuasan Pelanggan Jasa Transportasi Ojek Online (Studi pada Konsumen Gojek di Surabaya)". Hasil penelitian menunjukkan bahwa kualitas layanan dan harga berpengaruh terhadap kepuasan pelanggan.

\section{KESIMPULAN DAN SARAN}

\section{A. Kesimpulan}

Berdasarkan hasil penelitian dan pembahasan, maka dapat ditarik beberapa kesimpulan sebagai berikut.

1. Kualitas pelayanan berpengaruh signifikan terhadap kepuasan pelanggan pengguna jasa transportasi ojek online GrabBike di Kota Medan.

2. Persepsi harga berpengaruh signifikan terhadap kepuasan pelanggan pengguna jasa transportasi ojek online GrabBike di Kota Medan.

3. Citra merek berpengaruh signifikan terhadap kepuasan pelanggan pengguna jasa transportasi ojek online GrabBike di Kota Medan.

4. Kualitas pelayanan, persepsi harga, dan citra merek/secara bersama-sama berpengaruh signifikan terhadap kepuasan pelanggan pengguna jasa transportasi ojek online GrabBike di Kota Medan.

\section{B. Saran-saran}

Berdasarkan hasil penelitian, pembahasan, dan kesimpulan yang diperoleh, maka saran yang dapat diberikan sebagai berikut:

1. Bagi Perusahaan Grab

a. Berdasarkan hasil penelitian diketahui bahwa pada variabel kualitas pelayanan yang terletak pada indikator "empathy (penghargaan/ perhatian)" mendapat skor terendah (337), oleh karena itu, Grab disarankan untuk meningkatkan pelayanan dengan cara memberikan perhatian pada saat pelanggan memerlukan bantuan atau menanyakan apa kebutuhan pelanggan pada saat dalam perjalanan, meningkatkan kualitas pelayanan dan pada akhirnya dapat menciptakan kepuasan pelanggan.

b. Berdasarkan hasil penelitian diketahui bahwa pada variabel persepsi harga yang terletak pada indikator "kesesuaian harga dengan manfaat" mendapat skor terendah (323), oleh karena itu, Grab disarankan untuk selalu memonitoring dan mengevaluasi tarif Grab yang telah ditetapkan agar sesuai dengan dengan manfaat yang diharapkan konsumen yang menggunakan jasa Grab, sehingga konsumen akan mendapatkan kepuasan atas biaya yang dikeluarkan dengan manfaat yang diterima.

c. Berdasarkan hasil penelitian diketahui bahwa pada variabel citra merek yang terletak pada indikator "iklan online" mendapat skor terendah (334), oleh karena itu, Grab disarankan untuk memperhatikan faktor iklan online agar tercipta image positif di mata pelanggan, dengan cara: Grab disarankan untuk lebih sering membuat iklan-iklan secara online. Langkah-langkah ini diharapkan dapat membangun citra merek Grab yang positif dan pada akhirnya dapat menciptkan kepuasan pelanggan.

2. Peneliti selanjutnya dapat mengembangkan penelitian ini dengan menggunakan metode lain dalam meneliti kualitas pelayanan, persepsi harga, citra merek, dan kepuasan pelanggan, misalnya melalui wawancara mendalam terhadap responden, sehingga informasi yang diperoleh dapat lebih bervariasi daripada angket yang jawabannya telah tersedia. Selain itu, peneliti selanjutnya dapat menguji faktor-faktor 


\section{Volume 19 Nomor 2}

lainnya yang dapat mempengaruhi kepuasan pelanggan, seperti: kualitas produk dan nilai pelanggan.

\section{DAFTAR PUSTAKA}

Arikunto, Suharsimi. 2008. Prosedur Penelitian. Jakarta: Rineka Cipta.

Buttle, Francis. 2007. Custumer Relationship Managemen

(Manajemen.Hububgan Pelanggan). Bayumedia. Jakarta. Desrina.

Consuegra. D Molina. 2007. An Integrated Model of Price, Satisfaction and Loyality: An Empirical Analysis in Service Sector. Journal of ProductE Brand Managemen.

Engel, J.F, Blackwell, Rd, and Miniard, DW. 1990. Perilaku Konsumen Jilid I(Boediono. Terjemahan). Jakarta: Bina Rupa Aksara.

Ferdinand. 2006. Metode Penelitian Manajemen. Semarang: Badan. Penerbit Augusty Universitas Diponegoro.

Ghozali, Imam. 2011. Aplikasi Analisis Multivariate Dengan Program SPSS.

Semarang: Universitas Diponegoro.

Goetsch, D.L \& Davis, S, 1994 Introduction to Total Quality, Quality,Productivity, Competitiveness, Englewood Cliffs, NJ, Prentice HallInternational Inc.

Hair, et al. 1995. Multivariate Data Analysis 6 Ed. New Jersey: Pearson Education.

Herliza, Radita dan Saputri, Marheni Eka. (2016) tentang "Pengaruh Brand Image terhadap Kepuasan Pelanggan Studi pada Zara di Mall PVJ Bandung".Skripsi TidakDiterbitkan. Bandung: Universitas Padjajaran.

Hidayat, Ahmad. 2013. tentang “Analisis Pengaruh Citra Merek, Kualitas Produk, dan Harga terhadap Kepuasan Pelanggan serta Dampaknya terhadap Loyalitas Pelanggan (Studi Kasus Pada Member PT.Melia Sehat Sejahtera di UIN Syarif Hidayatullah Jakarta). Skripsi TidakDiterbitkan. Jakarta: UINSyarif Hidayatullah.

Irawan, Handi. 2002. 10 Prinsip Kepuasan Pelanggan, PT. Elex Media Komputindo.

Keller, Kevin Lane. (1993), Strategic Brand Management: Building, Measuring, and Managing Brand Equity. 2nd Edition. New Jersey, NJ.

Kotler Philip. 2010. Manajemen Pemasaran. (Hendra Teguh dan Ronny A. Rusli.

Terjemahan. Jakarta: PT. Prehallindo.

Kotler, P. dan Keller, K, L. 2007. Manajemen Pemasaran (Bejamin Molan,Pentj). Ed 12, Jilid 1\&2. Jakarta: Indeks.

Kotler, Philip dan AB. Susanto. 2000. Manajemen Pemasaran Indonesia. Buku 2.

Salemba empat. Jakarta.

Kotler, Philip dan Amstrong Gary. 2001. Prinsip-Prinsip Pemasaran. Alih bahasa Bob Sabran M.M. Edisi Bahasa Indonesia. Jilid 1. Jakarta: Erlangga.

Kotler, Philip dan Amstrong Gary. 2007. Prinsip-Prinsip Pemasaran. Alih bahasa Bob Sabran M.M. Edisi Bahasa Indonesia. Jilid 1. Jakarta: Erlangga.

Kotler, Philip. 2012. Manajemen Pemasaran Edisi Kesebelas. Jilid 2, Edisi BahasaIndonesia. Jakarta: Indeks.

Laila, dkk (2012: 5). Pengaruh Kualitas Pelayanan, Harga dan Nilai Pelanggan terhadap Kepuasan Pelanggan Pengguna Jasa Servis Bengkel AHAS 0002 Semarang Honda Center. Jurnal.

Mar'ati, Nafisa Choirul. 2016. Pengaruh Kualitas Layanan dan Harga terhadap Kepuasan Pelanggan Jasa Transportasi Ojek Online (Studi pada Konsumen Gojek di Surabaya). Jurnal. Program Studi Pendidikan Tata Niaga, Fakultas Ekonomi, Universitas Negeri Surabaya. 


\section{Volume 19 Nomor 2}

Melanesia, Herlinda. 2011. Pengaruh Kualitas Pelayanan terhadap Kepuasan Nasabah Bank pada Nasabah PD BPR Bank Sleman di Kabupaten Sleman). Skripsi Tidak Diterbitkan. Yogyakarta: FE UNY.

Nistanto, Reska K. 2016. Membandingkan Tarif Uber Motor, Gojek, dan Grab Bike. Kompas Edisi 13 April 2016 diunduh dari http://tekno.kompas.com/read/2016/04/13/10353087/Membandingkan.Tarif.UberMoto r.GoJek.dan.GrabBike.

Parasuraman, A. Zeithaml., Valerie, A., Berry, Leonard L. 1988. Servqual : A Mulitple-Item Scale for Measuring Consumer Perceptions of Service Quality. Journal of Retailing. Vol. 64 No.1. Hlm. 12-40.

Peter, J. Paul \& Jerry C. Olson. 1999. Consumer Behaviour Perilaku Konsumendan Strategi Pemasaran. Edisi ke empat. Jilid 1. Jakarta: Erlangga.

Retna, Dewi Wulan. 2013. Pengaruh Kualitas Produk dan Kualitas Pelayanan terhadap Kepuasan Pelanggan pada PDAM Tirta Pakuan Kota Bogor. Jurnal Online Mahasiswa Manajemen. Bogor: Sekolah Tinggi IlmuEkonomi Kesatuan.

Santosa, Budi Purbayu dan Ashari. 2005. Analisis Statistik dengan MicrosoftAxcel E SPSS. Yogyakarta: Andi Offset.

Stanton, William J. 1998. Prinsip Pemasaran. Jilid Idan II. (Terjemahan:Lamarto). Edisi Ketujuh. Jakarta: Erlangga.

Sugiyono. 2008. Statistika Untuk Penelitian. Bandung: CV. Alfabeta.

Sukmana, O. 2003. Dasar-dasar Psikologi Lingkungan. Malang: UMM Press.

Supranto. 1997. Pengukuran Tingkat Kepuasan Pelanggan Untuk MenaikkanPangsa Pasar. Jakarta: Rineka Cipta.

Sutisna. 2001. Perilaku Konsumen dan Komunikasi Pemasaran. Bandung: PT Remaja Rosdakarya.

Tjiptono, Fandy. 2008. Strategi Pemasaran, Edisi II Cetakan Ketiga. Yogyakarta:

Andi Offset.

Wahyuno, Cahyo. 2013. Pengaruh Kualitas Pelayanan dan Harga terhadap Kepuasan Konsumen Pengguna Jasa Hotel Anugerah Glagah Indah Temon Kulon Progo Yogyakarta. Skripsi Tidak Diterbitkan. Yogyakarta: FE UNY.

Walgito, Bimo. 1997. Pengatar Psikologi Umum. Yogyakarta: Andi Offset.

Yesenia dan Edward H Siregar. 2014. Pengaruh Kualitas Layanan dan Produk terhadap Kepuasan serta Loyalitas Pelanggan Kentucky Fried Chicken di Tangerang Selatan. Jurnal Manajemen dan Organisasi Vol V, No 3,Desember 2014. Departemen Manajemen, Fakultas Ekonomi danManajemen Institut Pertanian Bogor.

Zeithaml, Valerie A., Leonard Berry, and A. Parasuraman. 1996. The Behavioral Consequence Of Service Quality. Journal of Marketing, vol. 60. 